\title{
An Empirical Study on Different Tendencies toward Indulgence-Restraint Dimension from the Intercultural Perspective
}

\section{-In the Case of Guangdong Province}

\author{
Cai Jie, Luo Jing* \\ Shenzhen Tourism College, Jinan University, Shenzhen, China \\ Email: alicia_cai@163.com, "ivyluojing@163.com
}

Received 14 August 2015; accepted 13 November 2015; published 16 November 2015

Copyright (C) 2015 by authors and Scientific Research Publishing Inc.

This work is licensed under the Creative Commons Attribution International License (CC BY). http://creativecommons.org/licenses/by/4.0/

(c) (i) Open Access

\begin{abstract}
With the booming development of economic globalization nowadays, intercultural communication becomes more and more important. Based on Hofstede's indulgence-restraint dimension, this thesis aims to testify whether Hofstede's opinion that China is largely a restrained country, is correct in Guangdong Province, a coastal area with the largest population of China, and to investigate different groups of people's different tendencies toward indulgence and restraint. The study is carried out in Guangdong Province, because Guangdong is a special area which is one of the most rapidly developing areas in China and it locates next to Macau and Hong Kong, which may bring it with more different cultures and ideas. After conducting a questionnaire survey in Guangdong with a self-made questionnaire, the author gets the following findings. 1) The subjects generally show a stronger tendency toward indulgence than to restraint through comparing the mean scores of them respectively. 2) With respect to genders, males have fewer tendencies toward indulgence than females and more tendencies toward restraint. 3) Considering age groups, people aged more have more tendencies toward restraint and fewer tendencies toward indulgence. What's more, people aged from 18 to 60 are generally indulgence-oriented while people aged above 60 years old are generally restraint-oriented. 4) People with different disposable income groups and different educational backgrounds have no significant difference in general. All of them, generally, tend to be indulgent. The results of the study can help both foreign and local people to know more about Guangdong so as to enhance the mutual understanding to improve communication efficiency and help construct a harmonious society.
\end{abstract}

\section{Keywords}

Intercultural Communication, Indulgence, Restraint, Guangdong Province

\footnotetext{
${ }^{*}$ Corresponding author.
} 


\section{Introduction}

With the booming development of global economy nowadays, people travel around the world to do business, to have fun, to study, etc. However, due to the different cultures, people may find intercultural communication difficult.

Thus, many scholars have focused a lot on the study of intercultural communication. Intercultural communication study originated from the USA. As early as in 1959, Edward T. Hall published Silent Language, the famous book, which is usually regarded as the foundational work in the cross-cultural field, marking the beginning of intercultural study.

Hofstede, a Dutch management scholar, initially carried out a survey about cultural value among around 110,000 employees from 40 nations in IBM at the end of 1970s. After a detailed analysis of the data by statistical method, Geert Hofstede (1980) originally identified four cultural dimensions: 1) power distance; 2) uncertainty avoidance; 3) individualism-collectivism; 4) masculinity-femininity. And Hofstede’s study kept going. In 1987, he put forward the fifth dimension, which is “long-term/short-term orientation”. In 2010, the sixth and the latest dimension were carried out, the indulgence-restraint dimension.

In the theoretical framework of Hofstede, the present study mainly aims to testify if Guangdong Province with its fast economic development, special policies and location, is largely a restraint-oriented area as Hofstde defined China to be. What's more, this study also aims to explore the different tendencies toward IVR by different groups of people at different layers.

The significance of the study lies as below:

Firstly, the thesis can, to some extends, change the foreigners' stereotype toward people in Guangdong and help them have a full understanding of Guangdong cultural value to promote the mutual understanding of people from different cultures.

Secondly, the exploration of the different orientations between different groups of people toward the IVR dimension may enhance the mutual understanding and reduce the disagreement between different people.

To conclude, a clear realization of different tendencies toward IVR dimension of Guangdong Province plays an important role in successful intercultural communication, which can enhance the mutual understanding, improve working efficiency and help construct a harmonious society.

\section{Literature Review}

\subsection{Hofstede's Value Dimension Theory}

In 1980, after doing the comprehensive study on how values were influenced by culture in the workplace by investigating more than 100,000 individuals from 53 countries and regions, Hofstede published his finding, a theory of cultural value dimensions, which included individualism-collectivism, uncertainty avoidance, power distance, and masculinity-femininity. The fifth dimension, long-term/short-term orientation, was put forward in 1987.

It's also worth mentioning that Harry C. Triandis (1988) published his Cross-Cultural Studies of Individualism and Collectivism. In his research, Triandis found that orientations toward individualism and collectivism not only existed between different cultures but also within one culture, even within each society and each individual.

In 2010, based on Minkov's analysis of data from the World Value Survey, a new dimension was found, which was called indulgence-restraint dimension. It becomes the latest dimension of Hofstede's Value Dimension Theory. Among the 93 countries that Geert Hofstede and Michael Minkov (2010) calculated the IVR, China ranks 75, which means that generally China is a restrained culture.

Thus, in this study, the author supposes that the orientations towards IVR also exist within one culture, one society and one individual and tries to prove it in the empirical study.

\subsection{Definition of Indulgence versus Restraint (IVR)}

According to Hofstede (2010), the definition of IVR dimension is that,

Indulgence stands for a tendency to allow relatively free gratification of basic and natural human desires related to enjoying life and having fun. Its opposite pole, restraint, reflects a conviction that such gratification needs to be curbed and regulated by strict social norms (Hofstede, 281). 
And it should be noted that the gratification of desires on the indulgence side refers to enjoying life and having fun, not to gratifying human desires in general.

Thus, one of the two poles of this dimension is characterized by a perception that one can act as one pleases and indulge in leisurely and fun-related activities with friends or alone. At the other pole we find a perception that one's actions are restrained by various social norms and a feeling that leisurely activities, spending, and other similar types of indulgence are somewhat wrong.

In spite of Hofstede's IVR dimension, some other related studies have also been carried out. Some of them share some similarities with IVR, and some of them use IVR to correlate with some cultural behaviors and phenomena and explain them.

Michael Bond's (1992) Chinese Value Survey reported a dimension labeled "moral discipline”. One of its poles was "moral restraint" and the other is "lack of a strongly disciplined stance". As quoted by Hofstede,

The items that defined the positive pole of this dimension were 'moderation', 'keeping oneself disinterested and pure', and 'having few desires'. As these items are easy to associate with restraint, one would expect a negative correlation with indulgence (Hofstede, 288).

In 2004, Bond (2004) did another research on what he called social axioms with his associates. They got two cultural dimensions, one of which was called "societal cynicism", which is significantly and negatively correlated with IVR. Ulrich Schimmack and Ed Diener (2002) did a survey on how often people experience pleasant and unpleasant emotions and 6780 college students were involved. The result showed that students in more indulgent societies reported more often experiencing positive emotions. David Schimitt (2005) founded the International Sexuality Description Project and one of the cultural studies was sociosexuality. It turned out that "more indulgent societies have higher percentage of people who have nothing against lax norms concerning casual sex".

As for domestic literatures, Fang Ning (2009) carried out an exploratory study on the cultural values of China's post-1980s generation to examine the effects of nationality, employment, gender and age with Hofstede's latest VSM08. Sun Qingyan (2013) carried out an empirical study to investigate the cultural changes in China in the aspects of Power Distance, Uncertainty Avoidance, Indulgence and Context. Fu Yuxia (2013) did an empirical study on different tendencies of different groups of people toward individualism-collectivism dimension by interview and questionnaires, which provided helpful experience and methodology for this study.

As shown above, most of the related literatures are about the correlation between IVR and different cultural phenomena. There isn't any empirical study about IVR. However, this doesn't mean that there's no instructive study for the author. The methodology that Yuxia Fu used in her thesis is useful enough to provide the author with practical instructions.

\section{Methodology}

\subsection{Different Defining Attributes of IVR}

According to Hofstede and Minkov, some differences between indulgent and restrained societies are summarized in Table 1.

Table 1. Major differences between indulgent and restrained societies.

\begin{tabular}{ll}
\multicolumn{1}{c}{ Indulgent Society } & \multicolumn{1}{c}{ Restrained Society } \\
\hline $\begin{array}{l}\text { A perception of personal life control } \\
\text { Higher importance of leisure }\end{array}$ & A perception of helplessness: what happens to me is not my own doing. \\
Higher importance of having friends & Lower importance of leisure \\
Thrift is not very important. & Lower importance of having friends \\
Loose society & Thrift is important. \\
More likely to remember positive emotions & Tight society \\
Less moral discipline & Less likely to remember positive emotions \\
Positive attitude & Moral discipline \\
More extroverted personalities & Cynicism \\
Higher optimism & More neurotic personalities \\
Maintaining order in the nation is not given a high priority & More pessimism \\
\hline
\end{tabular}




\subsection{Research Questions}

The present thesis aims to answer the following questions:

1) Is the opinion by Hofstede that China is largely a restraint country, correct in Guangdong Province with the largest population of China?

2) Do different orientations toward IVR exist between males and females? And what is the tendency?

3) Do different orientations toward IVR exist between people with different levels of disposable income? And what is the tendency?

4) Do different orientations toward IVR exist between people from different age groups? And what is the tendency?

5) Do different orientations toward IVR exist between people from different education background? And what is the tendency?

In order to answer the five questions above, the author has conducted an experimental research with a selfmade questionnaire.

\subsection{Subjects}

Guangdong is chosen to be the targeted area of this study because of its particularity. Since the reform and opening policies have been carried out, China has experienced big changes, especially the coastal areas of China, such as Guangdong. With the rapid economic development, Guangdong has attracted people all around China, or we can say, all around the world to live and work here. It provides a multicultural environment of people living in Guangdong. On the other hand, being located next to Hong Kong and Macau makes its location special. Thus, the author wants to study on the IVR of people in Guangdong, such an open and special area.

Among the 158 questionnaires the author has handed out, there are 150 of them are valid. As the author's interactive circle is mainly in the west, the east and the south of Guangdong province, most of the questionnaires were handed out in these areas. In order to ensure the diversity of backgrounds of the subjects, the 150 subjects involved in the survey are mainly composed of college students, the parents of them and the friends of the parents. What's more, some people are also asked to finish the questionnaire in some public areas of Guangdong, such as public parks, supermarkets, etc. The brief information of the subjects is presented in Table 2.

\subsection{Design of the Questionnaire}

Based on the indulgence-restraint dimension of Hofstede's Value Dimension Theory, the questionnaire is divided into two parts named part A and part B, which are respectively related to indulgence and restraint. As indulgence-restraint orientation is assumed to exist in every individual, we thus need to compare the scores of each part and decide whether the individual is more indulgent or more restrained. What's more, in each part of the questionnaire, there are three aspects of life related with the statements, which are interpersonal relation, working style and personal life.

In the experiment, the respondents are asked to choose the most appropriate answer among the five provided answers which vary from "strongly agree" to "strongly disagree" with scores on the scale of 1 to 5 . Participants are familiar with the life-related settings, so they can instinctively decide on the most appropriate answer with their personal experience.

The study also intends to further check the specific and detailed different IVR orientations. So four variables are determined, which are genders, age groups, disposable income levels and educational backgrounds.

The experiment was carried out mainly by Wechat, the most popular on-line chatting tool in China. As most of the old don't use Wechat, the author also did the survey face to face in some public parks and supermarkets,

Table 2. Information of the subjects.

\begin{tabular}{|c|c|c|c|c|c|c|c|c|c|c|c|}
\hline \multirow[b]{2}{*}{ Group } & \multicolumn{2}{|c|}{ Gender } & \multicolumn{4}{|c|}{ Age } & \multicolumn{3}{|c|}{$\begin{array}{l}\text { Disposable Income } \\
\text { (yuan per month) }\end{array}$} & \multicolumn{2}{|c|}{ Education } \\
\hline & Male & Female & $18-30$ & $31-45$ & $46-60$ & $\begin{array}{c}\text { Above } \\
60\end{array}$ & $\begin{array}{l}\text { Below } \\
2500\end{array}$ & $2500-5000$ & $\begin{array}{l}\text { Above } \\
5000\end{array}$ & $\begin{array}{c}\text { Below } \\
\text { Vocational } \\
\text { College }\end{array}$ & $\begin{array}{l}\text { Vocational } \\
\text { College } \\
\text { and Above }\end{array}$ \\
\hline Number & 63 & 87 & 72 & 33 & 25 & 20 & 69 & 52 & 29 & 38 & 112 \\
\hline
\end{tabular}


where many old people could be found. At last, 158 questionnaires were completed, 150 of which are valid for the experiment. All the collected data was analyzed by using SPSS and Excel. The detailed results and data analysis will be reported in following part.

\section{Findings and Discussion}

This part mainly focuses on the detailed analyzed data, answering the specific research questions which are raised in the former part and tries to give reasonable explanations.

\subsection{A General Comparison between All the Subjects}

In the column 2 of Table 3, we can find that the means scores of part A and B of the 150 subjects are respectively 22.833 and 20.467. It means that the mean score of part A toward indulgence is slightly higher than that of part B toward restraint. In column 4, the significance (2-tailed) value is 0.000 , much smaller than 0.05 . According to the principle of statistics, if $\mathrm{P}$ is smaller than 0.05 , the difference is significant. Thus, the statistics is meaningful to the study. It indicates that people living in Guangdong generally display a tendency toward indulgence, which is different from Hofstede's point of view that Chinese people are generally restrained. According to the data, the mean score of each part is higher than the mid-point of the full score, which is 15 , indicating that these subjects present obvious tendencies toward both sides of orientations.

Since the reform and opening policies were carried out, China has experienced big changes, especially the coastal areas of China, such as Guangdong. With the rapid economic development, Guangdong has attracted people to live and work here. That provides a multicultural environment for people living in Guangdong. On the other hand, being located next to Hong Kong and Macau is another main factor. Thus, the culture of Guangdong has been changing from a restraint-oriented one, like the general of China, to a slightly indulgence-oriented one.

According to the third column of Table 4, the correlation value is -0.11 , which means there is a negative relationship between the scores of part A and part B, but the negative relationship is not significant enough, because -0.11 is slightly less than 0 . It indicates that an individual who gets a high mark on indulgence may not necessarily get low mark on restraint, and vice versa.

Seeing from the second row of Table 5, we can find that there are 102 subjects whose indulgent scores are higher than restraint scores, of which 86 subjects' scores of IVR are both higher than 15.16 subjects' indulgent scores are higher than 15 whereas the restraint scores are lower than 15 . The third row of the table shows that there are 39 subjects whose indulgent scores are lower than the restraint scores. Among them, 31 subjects' scores of part A \& B are both higher than 15, while 8 subjects' indulgent scores are smaller than or equal to 15 and their restraint scores are higher than 15. Finally we can find from the fourth row that there are only 9 subjects having the same score in both parts and the scores are both higher than 15.

The findings from Table 5 show that: 1) $68 \%$ of the subjects display more obvious tendency to indulgence than to restraint. 16 subjects show a much stronger tendency toward indulgence. 2) Only 39 subjects, 26\% of all, show a more obvious tendency toward restraint than toward indulgence. 3) 126 subjects' scores of I and R are both higher than 15 , the mid-point of the full score, which means that they have tendencies both to indulgence and to restraint.

The result has answered the first question mentioned in part three. Hofstede's opinion that China is largely a

Table 3. Comparison within all subjects.

\begin{tabular}{cccc}
\hline Part & N & Mean Score & P \\
\hline A & 150 & 22.833 & 0.000 \\
B & 150 & 20.467 & \\
\hline
\end{tabular}

Notes: A \& B is for part A \& B of the questionnaire. $\mathrm{N}$ is for the number of the subjects.

Table 4. Correlation analysis between part A \& B.

\begin{tabular}{ccc}
\hline Pair & N & Correlation \\
\hline A \& B & 150 & -0.11 \\
\hline
\end{tabular}


restraint country now is not correct in Guangdong Province. It also indicates that tendencies toward indulgence and restraint also exist in an individual for there are individuals who behave both indulgently and restrainedly and who behave either indulgently or restrainedly.

\subsection{Comparative Study between Genders}

In this part, the author aims to find out the different tendencies toward IVR from the perspective of genders.

\subsubsection{Findings between Genders}

As Table 6 shows, the values of $\mathrm{P}$ are both 0.000 in the two parts, which are lower than 0.05 . It implicates that there is significant difference between males and females in part A and part B. The mean scores of males and females in part A are 19.286 and 23.230 respectively, which indicate that males have less tendencies toward indulgence than females. In part B, the mean scores of males and females are respectively 21.508 and 17.713 , which mean that males have more tendencies toward restraint.

\subsubsection{Data Analysis between Genders}

According to Hofstede (1980), China belongs to masculine society and most men in China have owned higher social status and more responsibilities in the family and society due to their special social roles since long ago. Even though Guangdong is the forefront of the reform and opening policy, traditional ideas about males and

Table 5. Different tendencies within all subjects.

\begin{tabular}{|c|c|c|c|c|}
\hline & \multicolumn{2}{|c|}{ Type } & $\mathrm{N}$ & Percen \\
\hline \multirow{5}{*}{$\mathrm{I}>\mathrm{R}$} & $\mathrm{I}>15$ & $\mathrm{R}>15$ & 86 & 0.573 \\
\hline & $\mathrm{I}<15$ & $\mathrm{R}<15$ & 0 & 0 \\
\hline & $\mathrm{I}>15$ & $\mathrm{R} \leq 15$ & 16 & 0.107 \\
\hline & \multicolumn{2}{|c|}{ Total } & 102 & 0.680 \\
\hline & $\mathrm{I}>15$ & $\mathrm{R}>15$ & 31 & 0.207 \\
\hline \multirow{4}{*}{$\mathrm{I}<\mathrm{R}$} & $\mathrm{I}<15$ & $\mathrm{R}<15$ & 0 & 0 \\
\hline & $\mathrm{I} \leq 15$ & $\mathrm{R}>15$ & 8 & 0.053 \\
\hline & \multicolumn{2}{|c|}{ Total } & 39 & 0.260 \\
\hline & $\mathrm{I}>15$ & $\mathrm{R}>15$ & 9 & 0.060 \\
\hline \multirow{4}{*}{$\mathrm{I}=\mathrm{R}$} & $\mathrm{I}<15$ & $\mathrm{R}<15$ & 0 & 0 \\
\hline & $\mathrm{I}=15$ & $\mathrm{R}=15$ & 0 & 0 \\
\hline & \multicolumn{2}{|c|}{ Total } & 9 & 0.060 \\
\hline & \multicolumn{2}{|l|}{ Total } & 150 & 1 \\
\hline
\end{tabular}

Notes: I > R: Indulgence score is higher than restraint score. I $<\mathrm{R}$ : Indulgence score is lower than restraint score. $\mathrm{I}=\mathrm{R}$ : Indulgence score is equal to restraint score. $\mathrm{N}$ : Number of the corresponding subjects.

Table 6. General difference between genders.

\begin{tabular}{cccc}
\hline Part & Option & Mean & P \\
\hline \multirow{2}{*}{ A } & 1 & 19.286 & 0.000 \\
& 2 & 23.230 & \\
B & 1 & 21.508 & 0.000 \\
\hline
\end{tabular}

Notes: A: part A of the questionnaire. B: part B of the questionnaire. 1: males. 2: females. 
females haven't changed a lot. With the development of the economy and the growing cost of living, men are faced with more and more pressure, which can explain men's stronger tendencies toward restraint and weaker tendencies toward indulgence compared with women.

On the other hand, the role of women has actually changed. As women are getting further education, they are getting a better job and higher status in the society, which offers them more opportunities to choose the life they want. Thus, according to the statistics, women in Guangdong are changing the traditional stereotypes about Chinese females. They are even getting more indulgence-oriented compared with men in Guangdong.

\subsection{Comparative Study between Different Age Groups}

In this chapter, the author intends to find out the different orientations toward IVR dimension from angle of different age groups, including 18 - 30 years old, 31 - 45 years old, 46 - 60 years old and above 60 years old.

\subsubsection{Findings between Different Age Groups}

As we can see from Table 7, the values of P in part A and B are respectively 0.014 and 0.042 , which are both lower than 0.05 and mean that there are significant differences among the subjects. What's more, we can find in the table that the mean scores of group 1, 2 and 3 in part A are higher than those in part B, while the mean scores of group 4 in part A are lower than those in part B. That is to say, that people aged from 18 - 60 have more tendencies toward indulgence, while people aged above 60 have more tendencies toward restraint.

\subsubsection{Data Analysis between Different Age Groups}

Figure 1 is formed by the data the author got in Table 7. It shows a specific and vivid comparison between the

Table 7. General difference between different age groups.

\begin{tabular}{cccc}
\hline Part & Option & M & P \\
\hline & 1 & 25.333 & \\
2 & 23.963 & 0.014 \\
& 3 & 22.947 & \\
& 4 & 17.750 & \\
& 1 & 20.486 & 0.042 \\
& 2 & 21.667 & \\
\hline
\end{tabular}

Notes: 1: 18 - 30 y; 2: 31 - 45 y; 3: 46 - 60 y; 4: above 60 y.

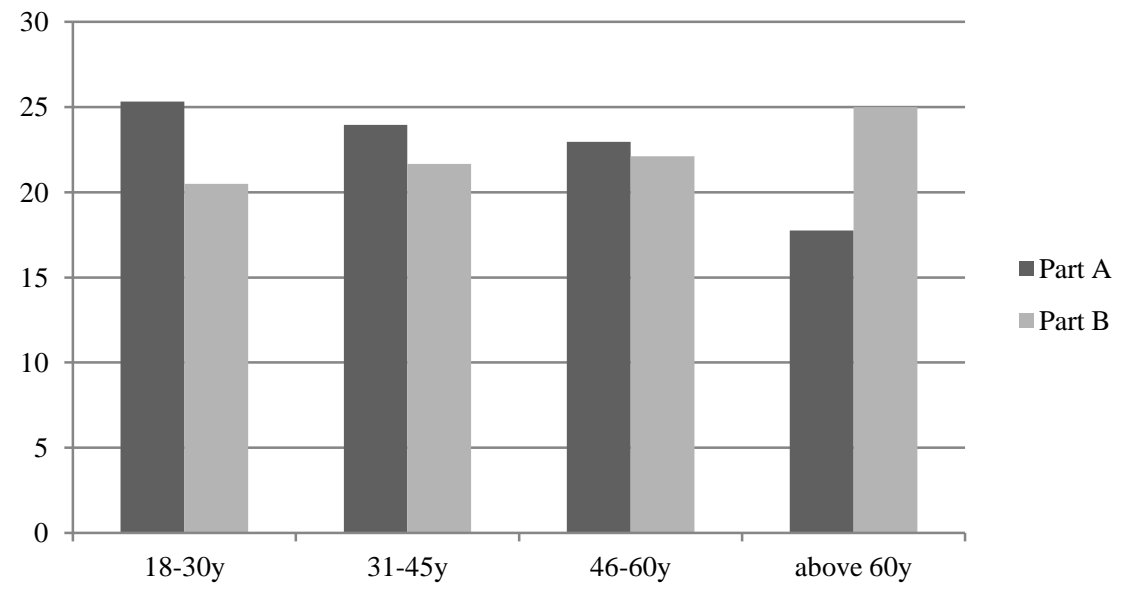

Figure 1. Comparisons between the mean scores of different age groups in different parts. 
mean scores of different age groups in different parts. The black pillar refers to the mean score of part A, while the grey pillar represents the mean score of part B. Thus, we can obviously find from the figure that: 1) The older people are, the less indulgent and the more restrained they become. 2) People aged from 18 to 60 have more tendencies toward indulgence, while people aged above 60 years old have more tendencies toward restraint.

Subjects in group 1, aged from 18 to 30, are China's post-1985 generation. They were born after the launching of the Reform and Opening-up Policy in 1978 and the practice of One Child Policy in 1979. They were mostly brought up in the one-child family and grew up in the period of rapid economic development. On the one hand, they grow up in the indulgence from parents and grandparents. On the other hand, they have a broader horizon of the world. As a result, they tend to be the most indulgent group compared with the other three groups.

Subjects in group 2 and 3 were mostly born after 1970s and 1960s. It's the generation linking the preceding and the following and wandering between tradition and modernity. When they were in their childhood, they were taught that personal interest should be restrained to achieve other greater goals, such as living in a thrift way to save money for the future. Things began to change when they became teenagers or in their twenties in the late 1980s. With a better economic environment and foreign ideas rushing into their mind due to the reform and opening-up policy, they realized that the pursuit of happiness and enjoying life are one's individual rights and indulgence is acceptable. Therefore, they also have more tendencies toward indulgence, but the tendencies are weaker compared with those of group 1.

In group 4, subjects were mainly born after 1950s in big families. Life was tougher in most of their life and they are more close-minded. Thus, this group tends to restrain themselves. Even now their life is getting better; they still tend to be restrained instead of being indulgent, just as it's become something deeply rooted in their mind.

\subsection{Comparative Study between People with Different Disposable Incomes and Different Educational Backgrounds}

\subsubsection{Findings between People with Different Disposable Incomes}

Table 8 shows that in part A and B, there are no significant differences between different disposable incomes levels, because the values of $\mathrm{P}$ are respectively 0.061 and 0.524 , which are both higher than 0.05 . What's more, the mean scores of this restraint part are very close to each other. However, the data indicates that all the subjects in different disposable incomes levels show a tendency toward indulgence because the mean scores in part A are all higher than those in part B. That is to say that, no matter how much disposable income the subjects get every month, they tend to be indulgent.

\subsubsection{Findings between People with Different Educational Backgrounds}

Table 9 shows that the value of $\mathrm{P}$ in the indulgence-oriented part is 0.065 , higher than 0.05 , and so is it in the restraint-oriented part (0.089). It means that both educational backgrounds show no significant difference in indulgence and restraint. It can be concluded by comparing the mean scores that the general subjects have tendencies toward indulgence.

Table 8. General difference between people with different disposable incomes.

\begin{tabular}{cccc}
\hline Part & Option & M & \\
\hline & 1 & 23.130 & \\
A & 2 & 21.865 & 0.061 \\
& 3 & 23.862 & \\
& 1 & 20.507 & 0.524 \\
B & 2 & 20.538 & \\
& 3 & 20.241 &
\end{tabular}

Notes: 1: below 2500 yuan per month; 2: 2500 - 5000 yuan per month; 3: above 5000 yuan per month. 
Table 9. General difference between people with different educational backgrounds.

\begin{tabular}{cccc}
\hline Part & Option & M & P \\
\hline A & 1 & 22.368 & 0.065 \\
& 2 & 23.009 & \\
B & 1 & 21.868 & 0.089 \\
\hline
\end{tabular}

Notes: 1: less than vocational college; 2: vocational college and above.

\subsubsection{Data Analysis between People with Different Disposable Incomes and Different Educational Backgrounds}

According to the data shown in Table 8 and Table 9, subjects with different disposable income and different educational backgrounds have no significant differences in general. And they generally have the tendency towards indulgence.

With the rapid development of Guangdong, people's living standard has increased. Thus, the disposable income doesn't significantly affect people's behavior in IVR. For example, even though people with lower disposable income cannot afford luxury goods, which may be regarded as one of the ways of indulgence, they still live a comparatively indulgent life in their way, such as being together with whom they love or buying something they want, which doesn't have to be very expensive. It's also the same reason for people with different educational backgrounds.

All in all, in a rapidly developing and opened area like Guangdong, no matter how people are comparatively rich or poor, comparatively high or low educated, they generally behave in a comparatively indulgence-oriented way.

\section{Conclusions}

Based on Hofstede's value dimension theory, the following findings are produced by analyzing the data in the present study.

First of all, the subjects generally show a slightly stronger tendency toward indulgence than to restraint. Thus, the idea that China is largely a restraint country is incorrect in Guangdong Province. With respect to genders, males have fewer tendencies toward indulgence and more tendencies toward restraint than females. Considering age groups, older people have more tendencies toward restraint and fewer tendencies toward indulgence. What's more, people aged from 18 to 60 are generally indulgence-oriented while people aged above 60 years old are generally restraint-oriented. It is also found that people with different disposable incomes and educational backgrounds have no significant difference in general. All of them, generally, tend to be indulgent.

\section{References}

Bond, M. (1992). The Process of Enhancing Cross-Cultural Competence in Hong Kong Organizations. International Journal of Intercultural Relations, 16, 395-412. http://dx.doi.org/10.1016/0147-1767(92)90030-X

Bond, M. (2004). Culture-Level Dimensions of Social Axioms and Their Correlates across 41 Cultures. Journal of CrossCultural Psychology, 35, 548-570. http://dx.doi.org/10.1177/0022022104268388

Fu Yuxia (2013). An Empirical Study on Different Tendencies toward Individualism and Collectivism—From Inter-Cultural Perspective. Thesis, Hefei: Anhui University.

Hofstede, G., \& Minkov, M. (2010). Cultures and Organizations: Software of the Mind. London: McGraw-Hill.

Hofstede, G. (1980). Culture's Consequences: International Difference in Work-Related Value. Hills, CA: Sage Publications.

Ning Fang (2009). An Exploratory Study on the Cultural Values of China's Post-1980s Generation-Examining the Effects of Nationality, Employment, Gender and Age with Hofstede's Latest VSM08. Thesis, Shanghai: Shanghai International Studies University.

Schimmack, U., \& Diener, E. (2002). Cultural Influences on the Relation between Pleasant Emotions and Unpleasant Emotions: Asian Dialectic Philosophies or Individualism-Collectivism? Cognition and Emotion, 16, 705-719.

http://dx.doi.org/10.1080/02699930143000590 
Schimitt, D. (2005). Sociosexuality from Argentina to Zimbabwe: A 48-Nation Study of Sex, Culture, and Strategies of Human Mating. Behavioral and Brain Science, 28, 247-311. http://dx.doi.org/10.1017/s0140525x05000051

Sun Qingyan (2013). The Changes of Cultural Patterns in China. Thesis, Xi'an: Xi'an International Studies University.

Triandis, H. C. (1988). Collectivism vs. Individualism: A Reconceptualization of a Basic Concept in Cross-Cultural Psychology. Cross-Cultural Studies of Personality, Attitudes and Cognition, 60-95. 


\section{Appendix}

\section{Questionnaire about Guangdong People's Different Tendencies toward IVR}

Thank you for your cooperation! As this questionnaire is anonymous, your answer is only for academic research without for any other purpose. According to your actual situation, please choose the most suitable answer and provide your real gender, age, disposable income and educational background. Scores range from 5 to 1 according to different options. Thank you!

Basic Information:

1. Are you Guangdong inhabitant?

Yes

No

2. Gender:

Female

Male

3. Age group:

18 - 30 years old

31 - 45 years old

46 - 60 years old above 60 years old

4. Monthly disposable income level (If student, please choose your monthly consumption level):

less than 2500 Yuan 2500 - 5000 Yuan more than 5000 Yuan

5. Educational background:

below vocational college

vocational college and above

\section{Part A}

1. I can decide on my life partner and I think that choosing the one I love is the most important thing.
Strongly agree
Agree
Not sure
Disagree
Strongly disagree

2. I like making friends with funny and free people. They bring happiness and surprise to life, even though sometimes they are in lack of plans.

Strongly agree__ Agree

Not sure

Disagree

Strongly disagree

3. I stop to have a rest when I feel tired at work.

Strongly agree

Agree

Not sure

Disagree

Strongly disagree

4. I like relaxing working environment and atmosphere, where colleagues can talk freely and frequently.
Strongly agree
Agree
Not sure
Disagree
Strongly disagree

5. I work hard and earn money in order to have higher-quality life, so I would make some spontaneous decisions, such as a quick-decided trip, even though I'm not very rich at that time.
Strongly agree
Agree
Not sure
Disagree
Strongly disagree

6. I like living for now and I think happiness is the most important thing, so we don't have to do anything that we don't like because of others' comments.

Strongly agree

Agree

Not sure

Disagree

Strongly disagree

Part B

1. Other people's opinions strongly affect my decision on my life partner.
Strongly agree
Agree
Not sure
Disagree
Strongly disagree

2. I like being with strict and self-disciplined people. They keep life in order and make everything go as planned.

Strongly agree___ Agree___ Not sure

3. I would forget about food and rest because of work.

4trongly agree_I think serious working environment is better for the working efficiency.

Strongly agree

Agree

Not sure

Disagree

Strongly disagree

5. I live a simple life style and save money for emergency.

Strongly agree

Agree___ Not sure

Disagree

6. When I'm out with friends, I always keep my unfinished homework or work in mind.

Strongly agree

Agree

Not sure

Disagree

Strongly disagree

Strongly disagree

trongly disagree 